\title{
Hydrothermal Synthesis, Characterization, and Optical Properties of Ce Doped $\mathrm{Bi}_{2} \mathrm{MoO}_{6}$ Nanoplates
}

\author{
Anukorn Phuruangrat, ${ }^{1}$ Nuengruethai Ekthammathat, ${ }^{2}$ Budsabong Kuntalue, ${ }^{3}$ Phattranit \\ Dumrongrojthanath, ${ }^{2}$ Somchai Thongtem, ${ }^{4,5}$ and Titipun Thongtem ${ }^{2}$
}

\author{
${ }^{1}$ Department of Materials Science and Technology, Faculty of Science, Prince of Songkla University, Hat Yai, Songkhla 90112, Thailand \\ ${ }^{2}$ Department of Chemistry, Faculty of Science, Chiang Mai University, Chiang Mai 50200, Thailand \\ ${ }^{3}$ Electron Microscopy Research and Service Center, Faculty of Science, Chiang Mai University, Chiang Mai 50200, Thailand \\ ${ }^{4}$ Department of Physics and Materials Science, Faculty of Science, Chiang Mai University, Chiang Mai 50200, Thailand \\ ${ }^{5}$ Materials Science Research Center, Faculty of Science, Chiang Mai University, Chiang Mai 50200, Thailand
}

Correspondence should be addressed to Anukorn Phuruangrat; phuruangrat@hotmail.com and

Titipun Thongtem; ttpthongtem@yahoo.com

Received 14 December 2013; Accepted 17 March 2014; Published 15 April 2014

Academic Editor: Ajay Soni

Copyright (C) 2014 Anukorn Phuruangrat et al. This is an open access article distributed under the Creative Commons Attribution License, which permits unrestricted use, distribution, and reproduction in any medium, provided the original work is properly cited.

Undoped and Ce doped $\mathrm{Bi}_{2} \mathrm{MoO}_{6}$ samples were synthesized by hydrothermal reaction at $180^{\circ} \mathrm{C}$ for $20 \mathrm{~h}$. Phase, morphology, atomic vibration, and optical properties were characterized by X-ray powder diffraction (XRD), X-ray photoelectron spectroscopy (XPS), Raman spectrophotometry, Fourier transform infrared (FTIR) spectroscopy, scanning electron microscopy (SEM), transmission electron microscopy (TEM), selected area electron diffraction (SAED), and UV-visible spectroscopy. In this research, the products were orthorhombic $\mathrm{Bi}_{2} \mathrm{MoO}_{6}$ nanoplates with the growth direction along the [0b0], including the asymmetric and symmetric stretching and bending modes of $\mathrm{Bi}-\mathrm{O}$ and $\mathrm{Mo}-\mathrm{O}$. Undoped and $\mathrm{Ce}$ doped $\mathrm{Bi}_{2} \mathrm{MoO}_{6}$ samples show a strong absorption in the UV region.

\section{Introduction}

Aurivillius family of structurally related oxides with chemical formula of $\mathrm{Bi}_{2} \mathrm{~A}_{n-1} \mathrm{~B}_{n} \mathrm{O}_{3 n+3}(\mathrm{~A}=\mathrm{Ca}, \mathrm{Sr}, \mathrm{Ba}, \mathrm{Pb}, \mathrm{Bi}, \mathrm{Na}, \mathrm{K}$, and $\mathrm{B}=\mathrm{Ti}, \mathrm{Nb}, \mathrm{Ta}, \mathrm{Mo}, \mathrm{W}$, and $\mathrm{Fe}$ ) was originally attractive material due to its layered structure and unique properties [1, $2]$. The perovskite-type blocks lead to variable layers along the $c$-axis due to the integer $n$ with $n=0,1,2,3,4,5$ and a typical "mica-like" two-dimensional structure [1]. $\mathrm{Bi}_{2} \mathrm{MoO}_{6}$ with narrow band gap of $2.9 \mathrm{eV}$ is a typical Aurivillius phase with its structure consisting of perovskite layers $\left(\mathrm{A}_{n-1} \mathrm{~B}_{n} \mathrm{O}_{3 n+1}\right)^{2-}$ between $\left(\mathrm{Bi}_{2} \mathrm{O}_{2}\right)^{2+}$ bismuth oxide layers, with a general formula $\left[\mathrm{Bi}_{2} \mathrm{O}_{2}\right]\left[\mathrm{A}_{n-1} \mathrm{~B}_{n} \mathrm{O}_{3 n+1}\right][3,4] . \mathrm{Bi}_{2} \mathrm{MoO}_{6}$ is an interesting material due to its unique physical properties for solar energy conversion, ion conduction, and photocatalysis for water splitting under visible-light irradiation and gas sensors $[1,2]$. Various synthetic methods for this material have been reported such as hydrothermal/solvothermal $[1,3,5]$, aerosol-spraying [4], coprecipitation [6], thermal evaporation [7], and hard-template method [8]. Recently, rare earth dopants have been excessively applied to modify optical properties of nanomaterials due to their possible transition of $4 \mathrm{f}$ electron configuration. Among them, cerium is one of the most interesting dopants due to its different electronic structure between $\mathrm{Ce}^{3+}\left(4 \mathrm{f}^{1} 5 \mathrm{~d}^{0}\right)$ and $\mathrm{Ce}^{4+}\left(4 \mathrm{f}^{0} 5 \mathrm{~d}^{0}\right)$, leading to different optical properties. It generates oxygen vacancies and bulk oxygen species, which have relatively high mobility. Thus they are more active for oxidation processes $[9,10]$.

In this paper, $0-3 \%$ Ce doped $\mathrm{Bi}_{2} \mathrm{MoO}_{6}$ crystallites were successfully synthesized by the hydrothermal process. Phase, 


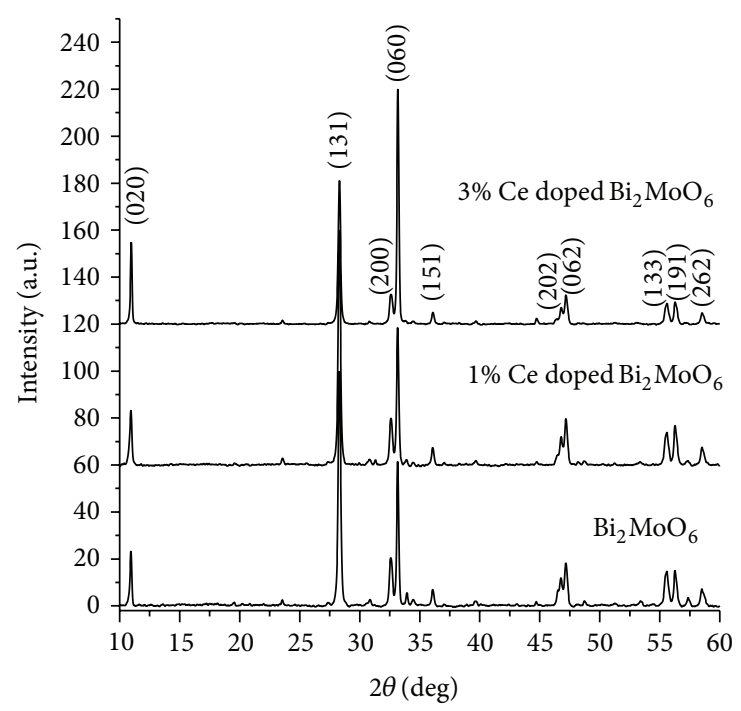

FIGURE 1: XRD patterns of the undoped, $1 \%$ Ce doped. and $3 \%$ Ce doped $\mathrm{Bi}_{2} \mathrm{MoO}_{6}$ samples synthesized by hydrothermal reaction at $180^{\circ} \mathrm{C}$ for $20 \mathrm{~h}$.

morphologies, and optical properties of the undoped and $\mathrm{Ce}$ doped $\mathrm{Bi}_{2} \mathrm{MoO}_{6}$ crystallites were intensively investigated.

\section{Experimental Procedures}

All the reagents were of analytical grade and used as received without further purification. In a typical experiment, $0.5 \mathrm{mmol} \mathrm{Na}_{2} \mathrm{MoO}_{4} \cdot 2 \mathrm{H}_{2} \mathrm{O}$ and $1 \mathrm{mmol} \mathrm{Bi}\left(\mathrm{NO}_{3}\right)_{3} \cdot 5 \mathrm{H}_{2} \mathrm{O}$ were dissolved in $60 \mathrm{~mL}$ deionized water to form solution $\mathrm{A}$ under 20 min magnetic stirring at room temperature. Concurrently, 1 and $3 \%$ by weight $\mathrm{Ce}\left(\mathrm{NO}_{3}\right)_{3} \cdot 6 \mathrm{H}_{2} \mathrm{O}$ were dissolved in $40 \mathrm{~mL}$ deionized water each to form solution $\mathrm{B}$ under $20 \mathrm{~min}$ magnetic stirring at room temperature. Then, solution B was slowly added to solution A to form homogeneous solutions with further stirring for $30 \mathrm{~min}$. Each solution of both with and without $\mathrm{Ce}^{3+}$ dopants was adjusted the level of acid or alkali until reaching at the $\mathrm{pH}$ of 10 using $3 \mathrm{M} \mathrm{NaOH}$, poured into each of stainless steel autoclave with a Teflon liner, and heated at $180^{\circ} \mathrm{C}$ for $20 \mathrm{~h}$. At the conclusion of the process, the autoclaves were cooled to room temperature. The products were separated centrifugally, washed with deionized water and absolute ethanol several times, and dried at $80^{\circ} \mathrm{C}$ for $12 \mathrm{~h}$.

The phase of the samples was characterized by $\mathrm{X}$ ray diffraction (XRD) using a Philips X'Pert MPD X-ray diffractometer with $\mathrm{CuK}_{\alpha}$ irradiation at $\lambda=1.5406 \AA$. The surface morphology was investigated by field emission scanning electron microscope (FE-SEM, JEOL JSM 6335F) and transmission electron microscope (TEM, JEOL, JEM2100) operated at the accelerating voltage of 35 and $200 \mathrm{kV}$, respectively. Raman and FTIR spectra were recorded on HORIBA JOBIN YVON T64000 Raman spectrometer with $50 \mathrm{~mW}$ and $514.5 \mathrm{~nm}$ wavelength Ar green laser and BRUKER TENSOR27 Fourier transform inferred (FTIR) spectrometer with $\mathrm{KBr}$ as a diluting agent and operated in the ranges of $100-1,000 \mathrm{~cm}^{-1}$ and $400-4,000 \mathrm{~cm}^{-1}$, respectively. X-ray photoelectron spectroscopy (XPS) of the products was carried out via an Axis Ultra DLD, Kratos Analytical Ltd., with a monochromated $\mathrm{Al} \mathrm{K}_{\alpha}(1486.6 \mathrm{eV})$ radiation as the excitation source at $15 \mathrm{kV}$. All obtained spectra were calibrated to a C1s electron peak at $285.1 \mathrm{eV}$. UV-visible absorption spectra of an ethanol suspension of $0-3 \%$ Ce doped $\mathrm{Bi}_{2} \mathrm{MoO}_{6}$ samples were recorded under a Lambda 25, Perkin Elmer UV-visible spectrophotometer.

\section{Results and Discussion}

The typical XRD patterns as shown in Figure 1 reveal the phase and purity of the as-obtained $0-3 \%$ Ce doped $\mathrm{Bi}_{2} \mathrm{MoO}_{6}$ samples. All peaks of the undoped and $\mathrm{Ce}$ doped $\mathrm{Bi}_{2} \mathrm{MoO}_{6}$ samples were specified as the single phase orthorhombic $\mathrm{Bi}_{2} \mathrm{MoO}_{6}$ structure (JCPDS card number 73-2020 [11]). The presence of sharp and intense peaks confirmed the formation of highly crystalline nanomaterials. Furthermore, the absence of any impurity related peaks indicates that $\mathrm{Ce}^{3+}$ ions were successfully doped into $\mathrm{Bi}_{2} \mathrm{MoO}_{6}$ nanostructure. However, the intensity ratio of the (060) peak to the (131) peak of $3 \% \mathrm{Ce}$ doped $\mathrm{Bi}_{2} \mathrm{MoO}_{6}$ sample is 1.66 , obviously larger than the undoped $\mathrm{Bi}_{2} \mathrm{MoO}_{6}$ which is equivalent to 0.60 [12]. This important result indicates that the crystal has special anisotropic growth along the [0b0] direction.

The morphology and particle sizes of the Ce doped $\mathrm{Bi}_{2} \mathrm{MoO}_{6}$ with different contents of $\mathrm{Ce}$ ions were investigated by SEM as shown in Figure 2. It can be seen that the samples were comprised of a large number of nanoplates with diameters ranging between 0.1 and $0.3 \mu \mathrm{m}$ and $<100 \mathrm{~nm}$ thick. The surfaces of these nanoplates are smooth. Interestingly, when the samples were doped by different Ce concentrations, Ce doped $\mathrm{Bi}_{2} \mathrm{MoO}_{6}$ are still to be nanoplates. These show that Ce doping concentration had little effect on the shape of the products. Clearly, morphology and particle sizes of 


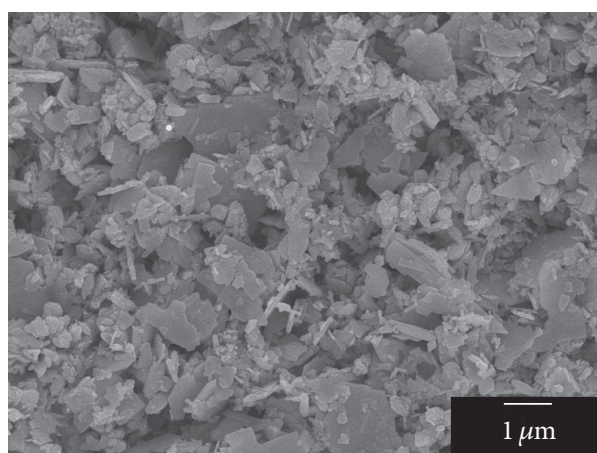

(a)

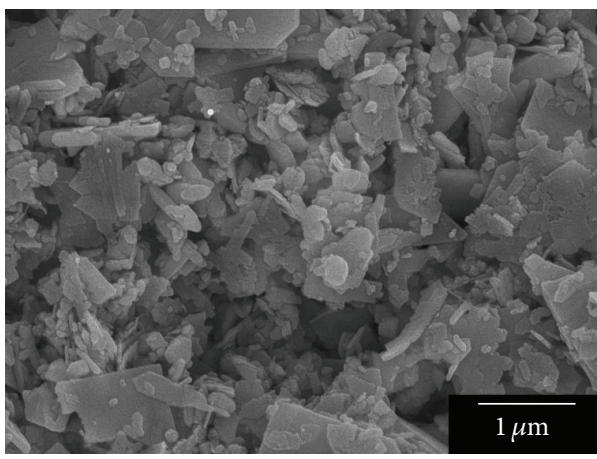

(c)

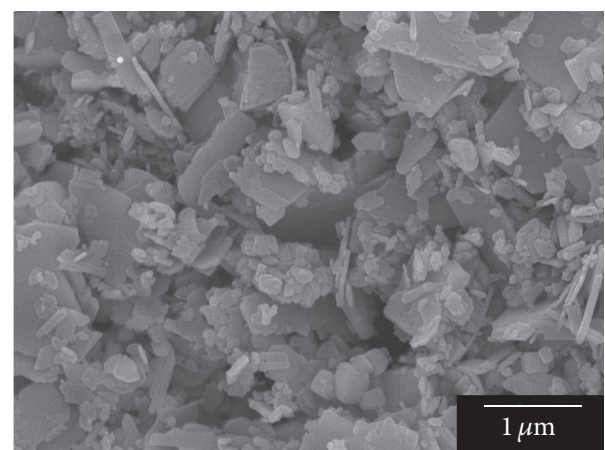

(b)

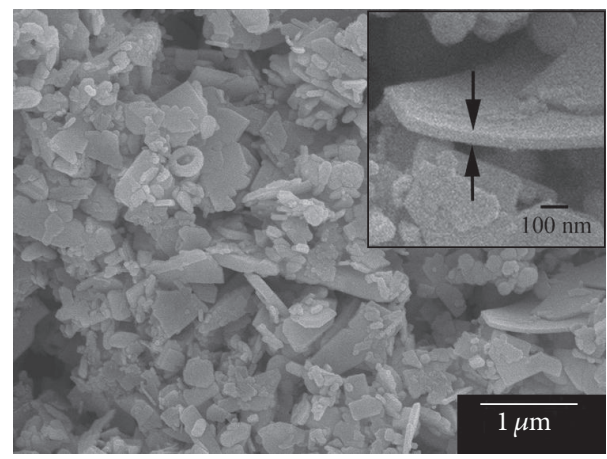

(d)

Figure 2: SEM images of the nanostructured $\mathrm{ZnO}$ of (a) undoped $\mathrm{Bi}_{2} \mathrm{MoO}_{6}$, (b) $1 \%$ Ce doped $\mathrm{Bi}_{2} \mathrm{MoO}_{6}$, and ((c), (d)) $3 \% \mathrm{Ce}$ doped $\mathrm{Bi}_{2} \mathrm{MoO}_{6}$.

the Ce doped $\mathrm{Bi}_{2} \mathrm{MoO}_{6}$ nanoplates were consistent with pure $\mathrm{Bi}_{2} \mathrm{WO}_{6}$.

More information of the structure was obtained by TEM observation as shown in Figure 3. It confirms that the undoped $\mathrm{Bi}_{2} \mathrm{MoO}_{6}$ nanoplates have an average diameter of about $0.2 \mu \mathrm{m}$, in accordance with the SEM analysis. Obviously, some of lighter color parts can be seen, due to the difference in the contrast in TEM, mainly related to the difference in thickness of the samples. Furthermore, the 3\% Ce doped $\mathrm{Bi}_{2} \mathrm{MoO}_{6}$ sample was composed of square nanoplates with $\sim 100 \mathrm{~nm}$ thick edge. The selected area electron diffraction (SAED) patterns clearly demonstrate the single crystalline nature of the nanoplates. Interestingly, the SAED patterns taken on the whole single nanoplate show single crystalline patterns with sharp diffraction bright spots, giving the [100] zone axis character of orthorhombic $\mathrm{Bi}_{2} \mathrm{MoO}_{6}$. Based on the above XRD results, it is reasonable to conclude that the nanoplates preferentially grew along the [010] direction.

The chemical composition of $3 \% \mathrm{Ce}$ doped $\mathrm{Bi}_{2} \mathrm{MoO}_{6}$ nanoplates was investigated by XPS spectroscopy as shown in Figure 4 and was calibrated using Cls peak at $285.1 \mathrm{eV}$. The $\mathrm{Bi} 4 \mathrm{f}$ peaks of the $3 \% \mathrm{Ce}$ doped $\mathrm{Bi}_{2} \mathrm{MoO}_{6}$ nanoplates appear at $159.52 \mathrm{eV}$ of $4 \mathrm{f}_{7 / 2}$ and $164.80 \mathrm{eV}$ of $4 \mathrm{f}_{5 / 2}$, corresponding to $\mathrm{Bi}^{3+}[4,13-15]$. Additional weak spin-orbit doublet peaks with binding energy of $157.92 \mathrm{eV}$ for $\mathrm{Bi} 4 \mathrm{f}_{7 / 2}$ and $163.40 \mathrm{eV}$ for $\mathrm{Bi}$ $4 \mathrm{f}_{5 / 2}$ are also detected, suggesting that some of bismuth exist as the $(+3-x)$ valence state [16]. Probably, the $\mathrm{Bi}^{(+3-x)}$ formal oxidation state could be attributed to the substoichiometric phase within the microsized plates [16]. The production of lower oxidation state results in the presence of oxygen vacancies inside. The Mo3d spectrum showed spin-orbit splitting of the Mo3d levels at $232.84 \mathrm{eV}$ and $236.00 \mathrm{eV}$, corresponding to the $3 \mathrm{~d}_{5 / 2}$ and $3 \mathrm{~d}_{3 / 2}$ orbitals $[4,13,17,18]$. The spin-orbit splitting between Mo3 $\mathrm{d}_{5 / 2}$ and $\mathrm{Mo}_{3 / 2} \mathrm{~d}_{3 / 2}$ signals of Ce doped $\mathrm{Bi}_{2} \mathrm{MoO}_{6}$ nanoplates was set to $3.16 \mathrm{eV}$ which are consistent with the previous reports [17]. However, single spin-orbit doublets showed peaks with binding energies of $231.3 \mathrm{eV}\left(\mathrm{Mo}_{\mathrm{d} / 2}\right)$ and $234.6 \mathrm{eV}\left(\mathrm{Mo3d}_{3 / 2}\right)$. These peaks are associated with Mo in formal (+6) oxidation state $[19,20]$. The $\mathrm{O}_{1 \mathrm{~s}}$ binding energy of $530.60 \mathrm{eV}$ was in agreement with the literature value [4]. The $\mathrm{O}$ element might come from two kinds of chemical states: crystal lattice oxygen and adsorbed oxygen. The triple peaks of $\mathrm{O}_{1 \mathrm{~s}}$ core at $529.30 \mathrm{eV}, 530.45 \mathrm{eV}$, and $531.32 \mathrm{eV}$ are attributed to the presence of $\mathrm{Bi}-\mathrm{O}, \mathrm{Mo}-$ $\mathrm{O}$ and $\mathrm{Ce}-\mathrm{O}$ bonds in $3 \% \mathrm{Ce}$ doped $\mathrm{Bi}_{2} \mathrm{MoO}_{6}$ sample [13]. The $\mathrm{O}_{1 \mathrm{~s}}$ binding energy of $532.58 \mathrm{eV}$ is due to the adsorbed oxygen. The XPS Ce3d peaks of cerium compounds are well known to be complicated because of hybridization of the Ce $4 \mathrm{f}$ orbital with ligand orbital and fractional occupancy of the valence $4 \mathrm{f}$ orbital. The XPS spectrum of the $3 \mathrm{~d}_{5 / 2}$ cerium level is therefore composed of three structures in the case of $\mathrm{CeO}_{2}$ and only two structures in the case of $\mathrm{Ce}_{2} \mathrm{O}_{3}$ or other $\mathrm{Ce}^{3+}$ compounds [21]. The peaks at $880.73 \mathrm{eV}, 884.34 \mathrm{eV}$, and $887.57 \mathrm{eV}$ are due to $3 \mathrm{~d}_{5 / 2}$ spin-orbit states, and those peaks at $898.68 \mathrm{eV}, 901.94 \mathrm{eV}$, and $905.11 \mathrm{eV}$ are due to the corresponding $3 \mathrm{~d}_{3 / 2}$ states. The spin-orbit splitting is about $17.6 \mathrm{eV}$. The highest binding energy peaks located at about $902 \mathrm{eV}$ and $884 \mathrm{eV}$ are the result of a Ce $3 \mathrm{~d}^{9} 4 \mathrm{f}^{1} \mathrm{O} 2 \mathrm{p}^{6}$ of $\mathrm{Ce}$ (III) 


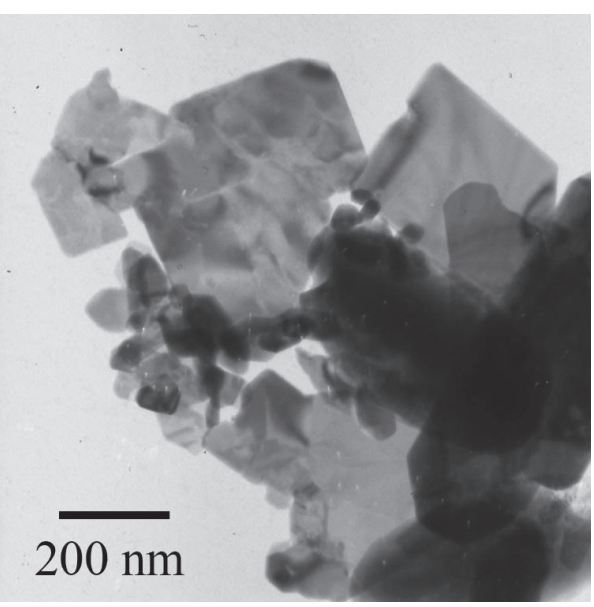

(a)

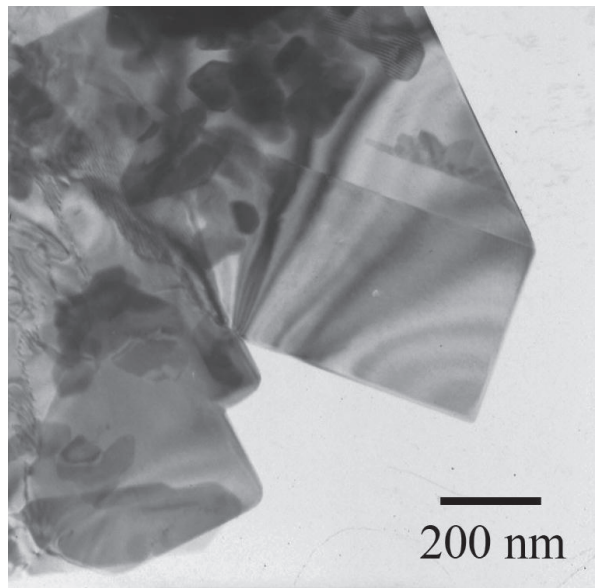

(c)

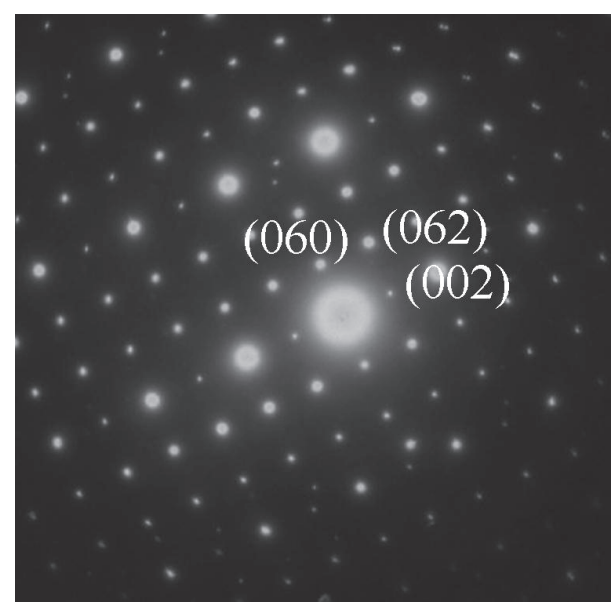

(b)

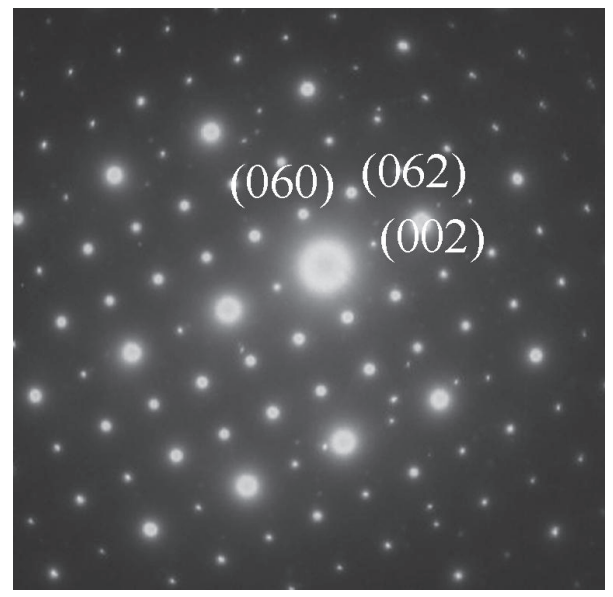

(d)

Figure 3: TEM images and SAED patterns of ((a), (b)) undoped $\mathrm{Bi}_{2} \mathrm{MoO}_{6}$, and ((c), (d)) 3\% Ce doped $\mathrm{Bi}_{2} \mathrm{MoO}_{6}$.

in $\mathrm{Ce}_{2} \mathrm{O}_{3}$ in final state. The lowest binding energies located at $898.68 \mathrm{eV}$ and $880.74 \mathrm{eV}$ are the result of $\mathrm{Ce} 3 \mathrm{~d}^{9} 4 \mathrm{f}^{2} \mathrm{O} 2 \mathrm{p}^{4}[10$, 21, 22]. The peaks at $887.57 \mathrm{eV}$ and $905.11 \mathrm{eV}$ are shakedown features resulting from the transfer of one or two electrons from a filled $\mathrm{O} 2 \mathrm{p}$ orbital to an empty Ce4f orbital, that is, $\mathrm{Ce} 3 \mathrm{~d}^{9} 4 \mathrm{f}^{2} \mathrm{O} 2 \mathrm{p}^{4}$ and $\mathrm{Ce} 3 \mathrm{~d}^{9} 4 \mathrm{f}^{1} \mathrm{O} 2 \mathrm{p}^{5} \mathrm{Ce}(\mathrm{IV})$ in the final states. Therefore, from the above results it is quite clear that there is coexistence of $\mathrm{Ce}^{3+}$ and $\mathrm{Ce}^{4+}$ in this sample [10, 21].

$\mathrm{Bi}_{2} \mathrm{MoO}_{6}$ crystal is built up of perovskite-like $\left(\mathrm{MoO}_{4}\right)^{2-}$ and fluorite-like $\left(\mathrm{Bi}_{2} \mathrm{O}_{2}\right)^{2+}$ layers. Its room temperature and ambient pressure structure is orthorhombic (space group symmetry $\mathrm{P} 2{ }_{1} \mathrm{ab}$ ). A standard group theoretical analysis for the $\mathrm{P} 2_{1} \mathrm{ab}$ room temperature phase of $\mathrm{Bi}_{2} \mathrm{MoO}_{6}$ unit cell leads to 108 degrees of freedom at the Brillouin zone center ( $\Gamma$ point). The optical modes are distributed among the irreducible representation of the factor group $\mathrm{C}_{2 v}$ as $26 \mathrm{~A}_{1}+$ $27 A_{2}+26 B_{1}+26 B_{2}$. Selection rules state that the $A_{1}, B_{1}$, and $B_{2}$ are both Raman and IR active whereas the $A_{2}$ modes are only Raman active [23-25].

Raman spectra of $0-3 \%$ Ce doped $\mathrm{Bi}_{2} \mathrm{MoO}_{6}$ samples are shown in Figure 5. It is well known that the bands in the $180-500 \mathrm{~cm}^{-1}$ range originated from the bending, wagging, and external modes by directly correlating the Mo$O$ bonds, and the $700-900 \mathrm{~cm}^{-1}$ region originated from the stretching vibration modes of the $\mathrm{MoO}_{6}$ octahedrons. Raman peaks at 323,345 , and $400 \mathrm{~cm}^{-1}$ corresponded to the $E_{u}$ symmetry bending modes. Raman modes near $293 \mathrm{~cm}^{-1}$ seemed to be from the $E_{g}$ bending vibration. The band at $144 \mathrm{~cm}^{-1}$ was assigned as the lattice modes of $\mathrm{Bi}^{3+}$ atoms mainly in the direction normal to the layers. The strong band at $792 \mathrm{~cm}^{-1}$ was assigned to $\mathrm{A}_{1 \mathrm{~g}}$ mode of $\mathrm{Mo}-\mathrm{O}$ stretching vibration of the distorted $\mathrm{MoO}_{6}$ octahedrons. The shoulder peak at $715 \mathrm{~cm}^{-1}$ was identified to the $E_{u}$ asymmetric stretching of $\mathrm{MoO}_{6}$ octahedrons involving the vibration of the equatorial oxygen atoms within the layers. The band at $841 \mathrm{~cm}^{-1}$ was assigned as the $\mathrm{A}_{2 u}$ symmetric and asymmetric stretching vibrations of the $\mathrm{MoO}_{6}$ octahedrons, relating to the motion of the apical oxygen atoms normal to the layers. When the $\mathrm{Ce}$ was doped into the samples, the strong bands at $792 \mathrm{~cm}^{-1}$ and two shoulder peaks at 715 and $840 \mathrm{~cm}^{-1}$ also slightly shifted to 713,791 , and $838 \mathrm{~cm}^{-1}$, confirming an effective substitution 


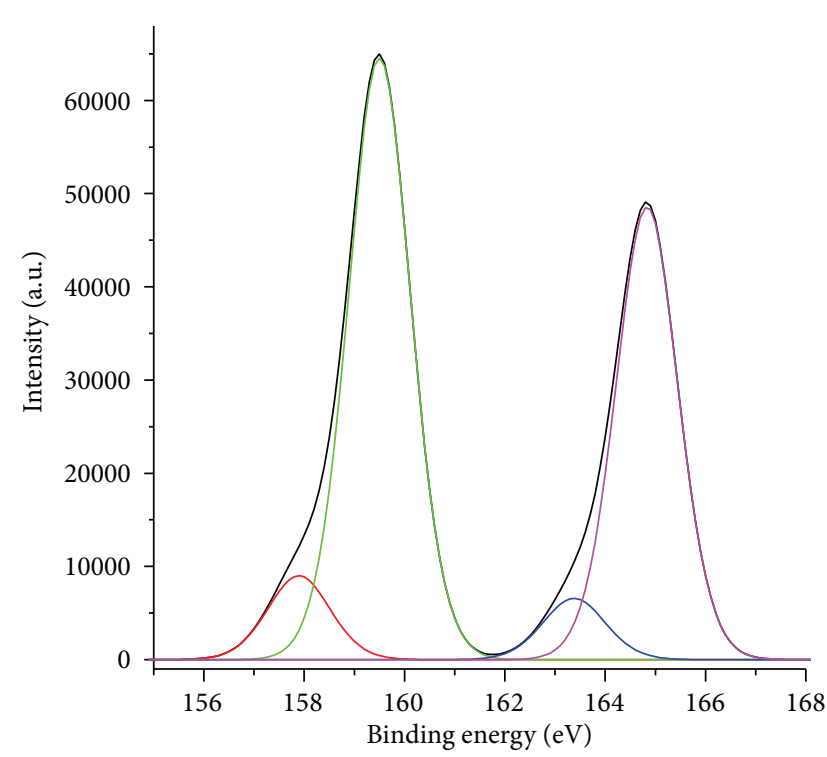

(a)

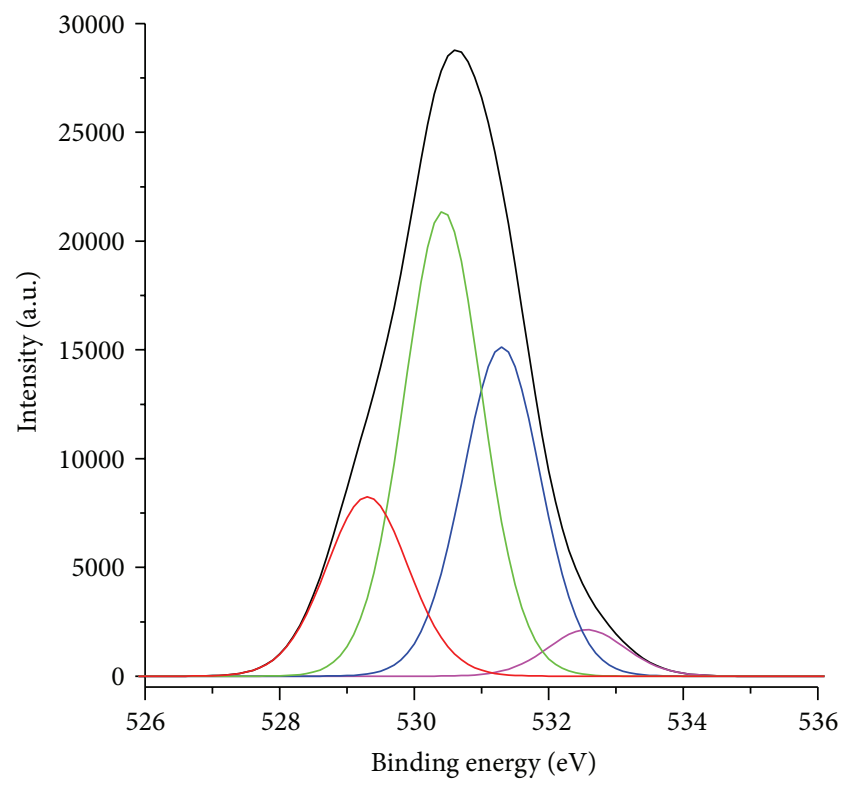

(c)

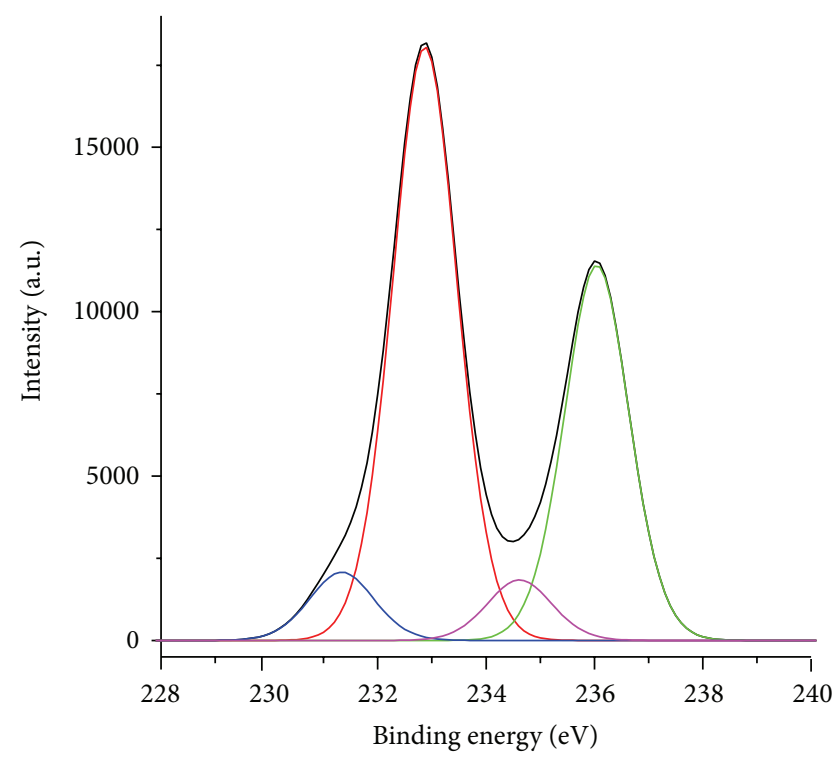

(b)

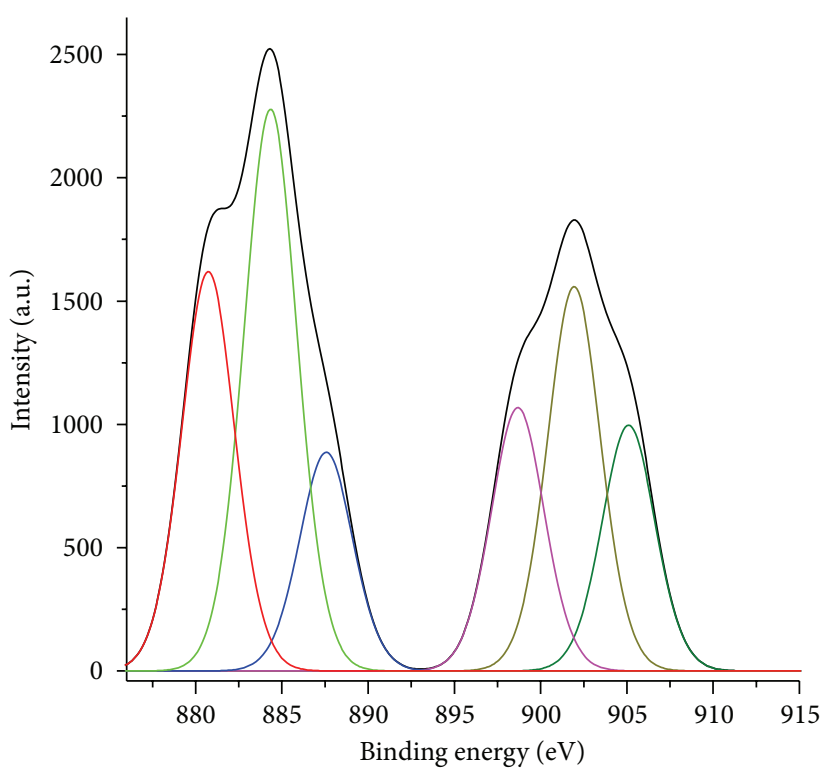

(d)

Figure 4: XPS spectra of the $3 \%$ Ce doped $\mathrm{Bi}_{2} \mathrm{MoO}_{6}$ nanoplates for (a) Bi4f, (b) Mo3d, (c) $\mathrm{O}_{1 \mathrm{~s}}$, and (d) Ce4f.

of $\mathrm{Bi}^{3+}$ ions by $\mathrm{Ce}^{3+}$ ions in the as-prepared nanocrystals, as also revealed by the XRD analysis [23-26].

FTIR spectra of the samples (Figure 6) show the band in the $400-900 \mathrm{~cm}^{-1}$ range, corresponding to $\mathrm{Bi}-\mathrm{O}$ stretching and bending, Mo-O stretching, and $\mathrm{Mo}-\mathrm{O}-\mathrm{Mo}$ bridging stretching modes of $\mathrm{Bi}_{2} \mathrm{MoO}_{6}$. The bands at 843 and $797 \mathrm{~cm}^{-1}$ were assigned as the asymmetric and symmetric stretching modes of $\mathrm{MoO}_{6}$ relating to vibrations of apical oxygen atoms, respectively. The $731 \mathrm{~cm}^{-1}$ mode was attributed to the asymmetric stretching vibration of the equatorial oxygen atoms of $\mathrm{MoO}_{6}$ octahedrons. Those at 603 and $570 \mathrm{~cm}^{-1}$ were specified as the bending vibrations of $\mathrm{MoO}_{6}$. Weak bands at 409 and $448 \mathrm{~cm}^{-1}$ were attributed to the stretching and bending vibrations of $\mathrm{BiO}_{6}$ octahedrons $[2,26]$.
The UV-visible absorption spectra of the undoped and Ce doped $\mathrm{Bi}_{2} \mathrm{MoO}_{6}$ are shown in Figure 7. They show the strong absorption in the UV and visible-light regions. It should be noted that the maximum absorption was detected at $321 \mathrm{~nm}$ for $3 \%$ Ce doped $\mathrm{Bi}_{2} \mathrm{MoO}_{6}$, obviously blue shifted compared to that of $\mathrm{Bi}_{2} \mathrm{MoO}_{6}$ at $383 \mathrm{~nm}$. For a crystalline semiconductor, the optical absorption near the band edge follows the equation $\alpha h v=A\left(h v-E_{g}\right)^{n / 2}$, where $\alpha, v, E_{g}$, and $A$ are the absorption coefficient, photonic frequency, energy gap, and a constant, respectively $[2,3]$. For $\mathrm{Bi}_{2} \mathrm{MoO}_{6}$, the value of $n$ is 1 for the direct transition. The plot of $(\alpha h v)^{2}$ versus photon energy $(h v)$ of undoped and Ce doped $\mathrm{Bi}_{2} \mathrm{WO}_{6}$ was estimated from the intercepts of the tangents to the plots which are $1.86 \mathrm{eV}$ for pure $\mathrm{Bi}_{2} \mathrm{MoO}_{6}$ and $2.04 \mathrm{eV}$ for $3 \%$ 


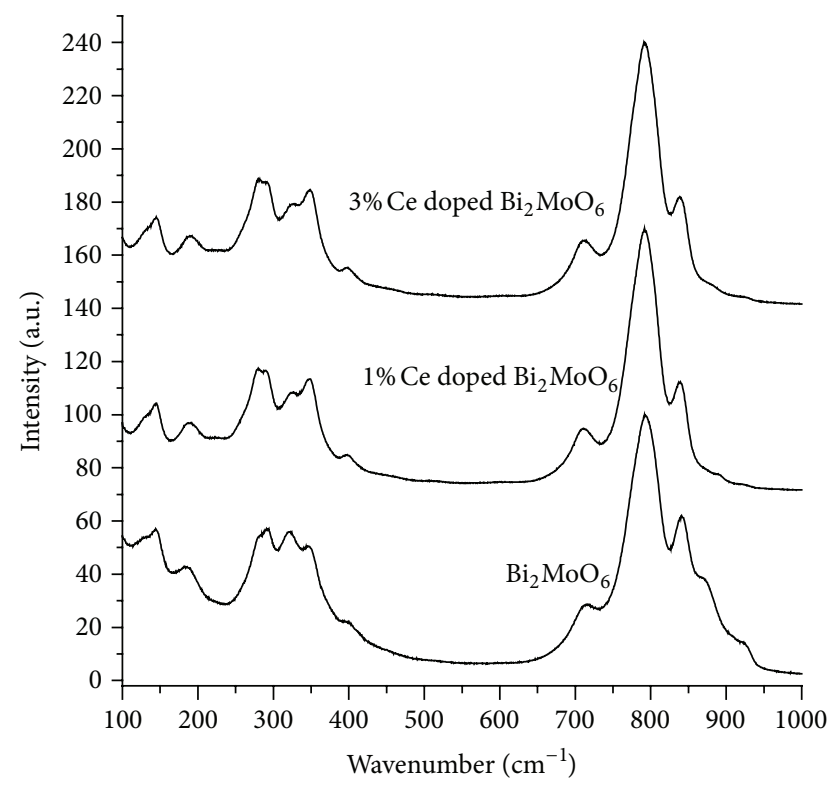

Figure 5: Raman spectra of undoped, 1\% Ce doped, and 3\% Ce doped $\mathrm{Bi}_{2} \mathrm{MoO}_{6}$ samples.

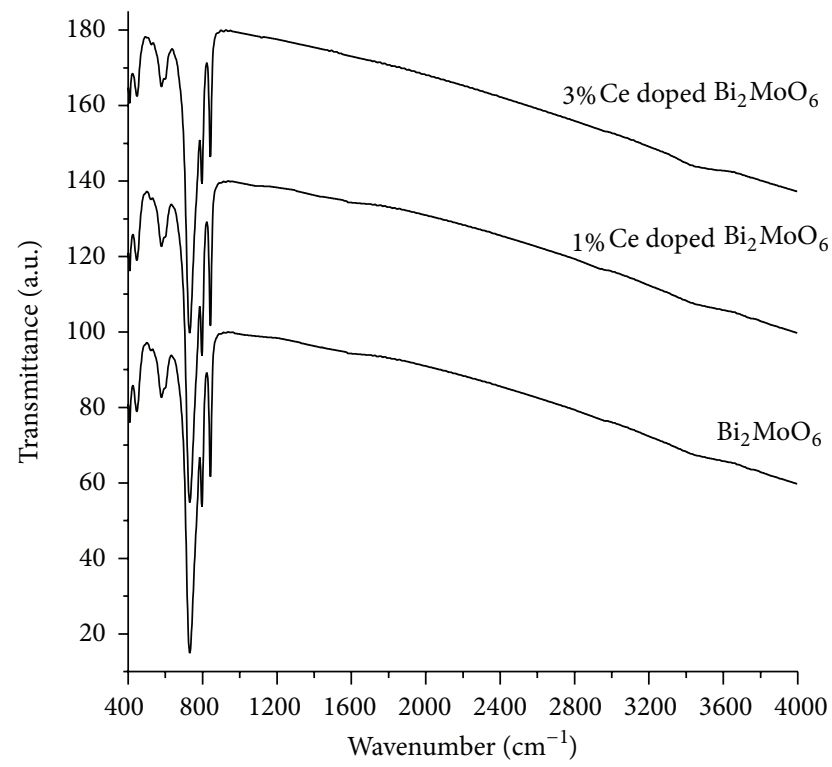

Figure 6: FTIR spectra of undoped, $1 \%$ Ce doped, and 3\% Ce doped $\mathrm{Bi}_{2} \mathrm{MoO}_{6}$ samples.

Ce doped $\mathrm{Bi}_{2} \mathrm{MoO}_{6}$ which imply the possible application for visible-light photocatalysis.

\section{Conclusions}

0-3\% Ce doped orthorhombic $\mathrm{Bi}_{2} \mathrm{MoO}_{6}$ nanoplates were successfully synthesized by the hydrothermal method. The experimental results presented that the as-synthesized products were orthorhombic $\mathrm{Bi}_{2} \mathrm{MoO}_{6}$ with the growth along the [010] direction. UV-visible absorption spectra show strong absorption due to the intrinsic energy gap transition of $\mathrm{Bi}_{2} \mathrm{MoO}_{6}$.

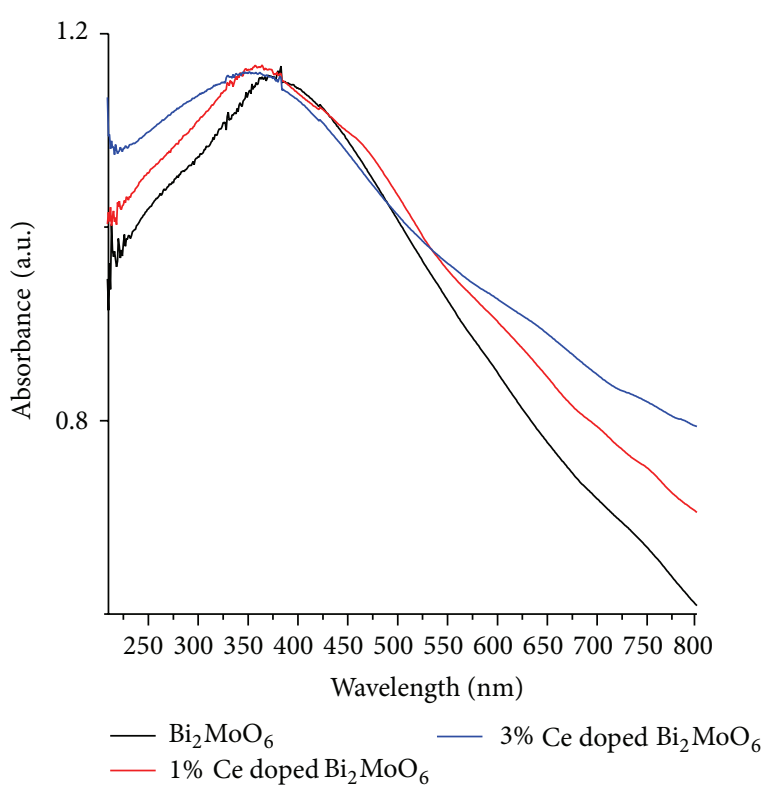

(a)

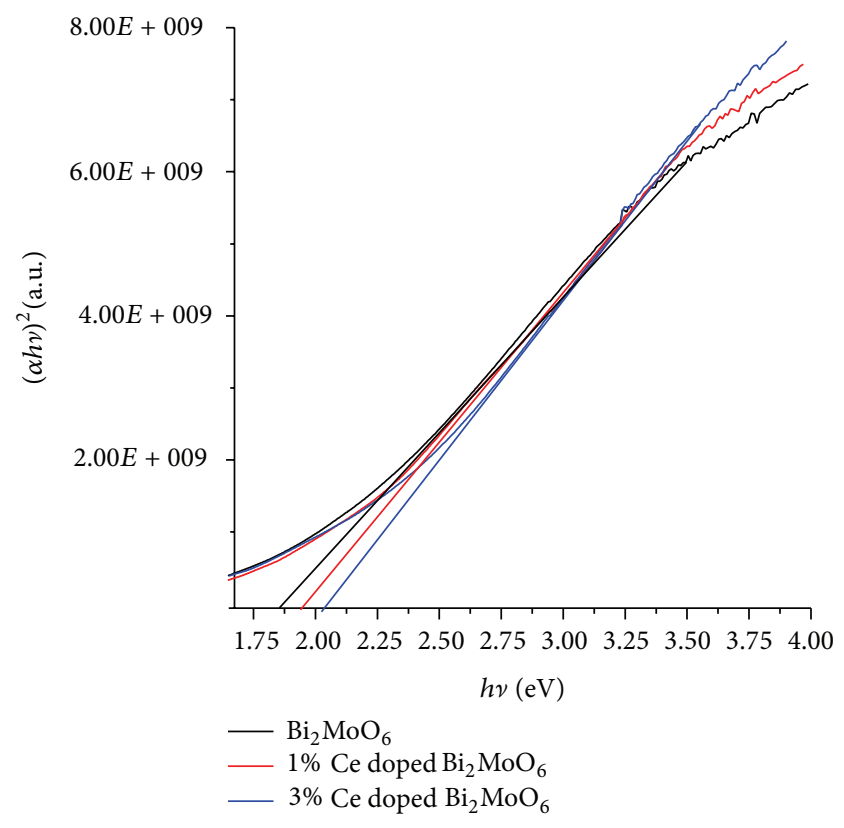

(b)

Figure 7: (a) UV-visible absorption and (b) $(\alpha h \nu)^{2}$ versus $h \nu$ curves of undoped, $1 \% \mathrm{Ce}$ doped, and $3 \% \mathrm{Ce}$ doped $\mathrm{Bi}_{2} \mathrm{MoO}_{6}$ samples.

\section{Conflict of Interests}

The authors declare that there is no conflict of interests regarding the publication of this paper.

\section{Acknowledgment}

The authors are extremely grateful to the Prince of Songkla University, Hat Yai, Songkhla, Thailand, for providing financial support through contract no. SCI560002S. 


\section{References}

[1] Y. Shi, S. Feng, and C. Cao, "Hydrothermal synthesis and characterization of $\mathrm{Bi}_{2} \mathrm{MoO}_{6}$ and $\mathrm{Bi}_{2} \mathrm{WO}_{6}$," Materials Letters, vol. 44, no. 3, pp. 215-218, 2000.

[2] M. Zhang, C. Shao, P. Zhang et al., " $\mathrm{Bi}_{2} \mathrm{MoO}_{6}$ microtubes: controlled fabrication by using electrospun polyacrylonitrile microfibers as template and their enhanced visible light photocatalytic activity," Journal of Hazardous Materials, vol. 225-226, pp. 155-163, 2012.

[3] C. Xu, D. Zou, L. Wang, H. Luo, and T. Ying, " $\gamma-\mathrm{Bi}_{2} \mathrm{MoO}_{6}$ nanoplates: surfactant-assisted hydrothermal synthesis and optical properties," Ceramics International, vol. 35, no. 5, pp. 2099-2102, 2009.

[4] Y. Miao, G. Pan, Y. Huo, and H. Li, "Aerosol-spraying preparation of $\mathrm{Bi}_{2} \mathrm{MoO}_{6}$ : a visible photocatalyst in hollow microspheres with a porous outer shell and enhanced activity," Dyes Pigments, vol. 99, pp. 382-389, 2013.

[5] X. Wang, F. Gu, L. Li, G. Fang, and X. Wang, "A facile mixedsolvothermal route to $\gamma-\mathrm{Bi}_{2} \mathrm{MoO}_{6}$ nanoflakes and their visiblelight-responsive photocatalytic activity," Materials Research Bulletin, vol. 48, pp. 3761-3765, 2013.

[6] A. Martínez-de la Cruz and S. Obregón Alfaro, "Synthesis and characterization of $\gamma-\mathrm{Bi}_{2} \mathrm{MoO}_{6}$ prepared by coprecipitation: photoassisted degradation of organic dyes under vis-irradiation," Journal of Molecular Catalysis A: Chemical, vol. 320, no. 1-2, pp. 85-91, 2010.

[7] E. L. Cuéllar, A. Martínez-De La Cruz, K. H. L. Rodríguez, and U. O. Méndez, "Preparation of $\gamma-\mathrm{Bi}_{2} \mathrm{MoO}_{6}$ thin films by thermal evaporation deposition and characterization for photocatalytic applications," Catalysis Today, vol. 166, no. 1, pp. 140-145, 2011.

[8] W. Yin, W. Wang, and S. Sun, "Photocatalytic degradation of phenol over cage-like $\mathrm{Bi}_{2} \mathrm{MoO}_{6}$ hollow spheres under visiblelight irradiation," Catalysis Communications, vol. 11, no. 7, pp. 647-650, 2010.

[9] J. Xie, D. Jiang, M. Chen et al., "Preparation and characterization of monodisperse Ce-doped $\mathrm{TiO}_{2}$ microspheres with visible light photocatalytic activity," Colloids and Surfaces A: Physicochemical and Engineering Aspects, vol. 372, no. 1-3, pp. 107-114, 2010.

[10] M. Nasir, S. Bagwasi, Y. Jiao, F. Chen, B. Tian, and J. Zhang, "Characterization and activity of the Ce and $\mathrm{N}$ co-doped $\mathrm{TiO}_{2}$ prepared through hydrothermal method," Chemical Engineering Journal, vol. 236, pp. 388-397, 2014.

[11] Powder Diffract. File, JCPDS Internat. Centre Diffract. Data, Pa, USA, 2001.

[12] Y. Zheng, F. Duan, J. Wu, L. Liu, M. Chen, and Y. Xie, "Enhanced photocatalytic activity of bismuth molybdates with the preferentially exposed 010 surface under visible light irradiation," Journal of Molecular Catalysis A: Chemical, vol. 303, no. 1-2, pp. 9-14, 2009.

[13] T. Zhou, J. Hu, and J. Li, " $\mathrm{Er}^{3+}$ doped bismuth molybdate nanosheets with exposed 010 facets and enhanced photocatalytic performance," Applied Catalysis B: Environmental, vol. 110, pp. 221-230, 2011.

[14] C. Wang, C. Shao, Y. Liu, and L. Zhang, "Photocatalytic properties $\mathrm{BiOCl}$ and $\mathrm{Bi}_{2} \mathrm{O}_{3}$ nanofibers prepared by electrospinning," Scripta Materialia, vol. 59, no. 3, pp. 332-335, 2008.
[15] B. Yuan, C. Wang, Y. Qi et al., "Decorating hierarchical $\mathrm{Bi}_{2} \mathrm{MoO}_{6}$ microspheres with uniformly dispersed ultrafine Ag nanoparticles by an in situ reduction process for enhanced visible lightinduced photocatalysis," Colloids and Surfaces A, vol. 425, pp. 99-107, 2013.

[16] L. Wu, J. Bi, Z. Li, X. Wang, and X. Fu, "Rapid preparation of $\mathrm{Bi}_{2} \mathrm{WO}_{6}$ photocatalyst with nanosheet morphology via microwave-assisted solvothermal synthesis," Catalysis Today, vol. 131, pp. 15-20, 2008.

[17] Z. Li, L. Gao, and S. Zheng, "SEM, XPS, and FTIR studies of $\mathrm{MoO}_{3}$ dispersion on mesoporous silicate MCM-41 by calcination," Materials Letters, vol. 57, no. 29, pp. 4605-4610, 2003.

[18] X. Zeng, X. Zhang, M. Yang, and Y. Qi, "A facile hydrothermal method for the fabrication of one-dimensional $\mathrm{MoO}_{3}$ nanobelts," Materials Letters, vol. 112, pp. 87-89, 2013.

[19] B. M. Sánchez, T. Brousse, C. R. Castro, V. Nicolosi, and P. S. Grant, "An investigation of nanostructured thin film $\alpha-\mathrm{MoO}_{3}$ based supercapacitor electrodes in an aqueous electrolyte," Electrochimica Acta, vol. 91, pp. 253-260, 2013.

[20] M. Rouhani, Y. L. Foo, J. Hobley et al., "Photochromism of amorphous molybdenum oxide films with different initial Mo5+ relative concentrations," Applied Surface Science, vol. 273, pp. 150-158, 2013.

[21] H. Borchert, Y. V. Frolova, V. V. Kaidiev et al., "Electronic and chemical properties of nanostructured cerium dioxide doped with praseodymium," Journal of Physical Chemistry B, vol. 109, no. 12, pp. 5728-5738, 2005.

[22] M. Faisal, A. A. Ismail, A. A. Ibrahim, H. Bouzid, and S. A. AlSayari, "Highly efficient photocatalyst based on Ce doped $\mathrm{ZnO}$ nanorods: controllable synthesis and enhanced photocatalytic activity," Chemical Engineering Journal, vol. 229, pp. 225-233, 2013.

[23] M. MącZka, P. T. C. Freire, C. Luz-Lima, W. Paraguassu, J. Hanuza, and J. Mendes Filho, "Pressure-induced phase transitions in ferroelectric $\mathrm{Bi}_{2} \mathrm{MoO}_{6}$-a Raman scattering study," Journal of Physics Condensed Matter, vol. 22, no. 1, Article ID 015901, 2010.

[24] M. Mçcka, W. Paraguassu, L. Macalik, P. T. C. Freire, J. Hanuza, and J. Mendes Filho, "A Raman scattering study of pressureinduced phase transitions in nanocrystalline $\mathrm{Bi}_{2} \mathrm{MoO}_{6}$," Journal of Physics Condensed Matter, vol. 23, no. 4, Article ID 045401, 2011.

[25] M. Mçcka, L. Macalik, K. Hermanowicz, L. Kępiński, and J. Hanuza, "Synthesis and phonon properties of nanosized aurivillius phase of $\mathrm{Bi}_{2} \mathrm{MoO}_{6}$," Journal of Raman Spectroscopy, vol. 41, no. 10, pp. 1289-1296, 2010.

[26] L. Zhang, T. Xu, X. Zhao, and Y. Zhu, "Controllable synthesis of $\mathrm{Bi}_{2} \mathrm{MoO}_{6}$ and effect of morphology and variation in local structure on photocatalytic activities," Applied Catalysis B: Environmental, vol. 98, no. 3-4, pp. 138-146, 2010. 

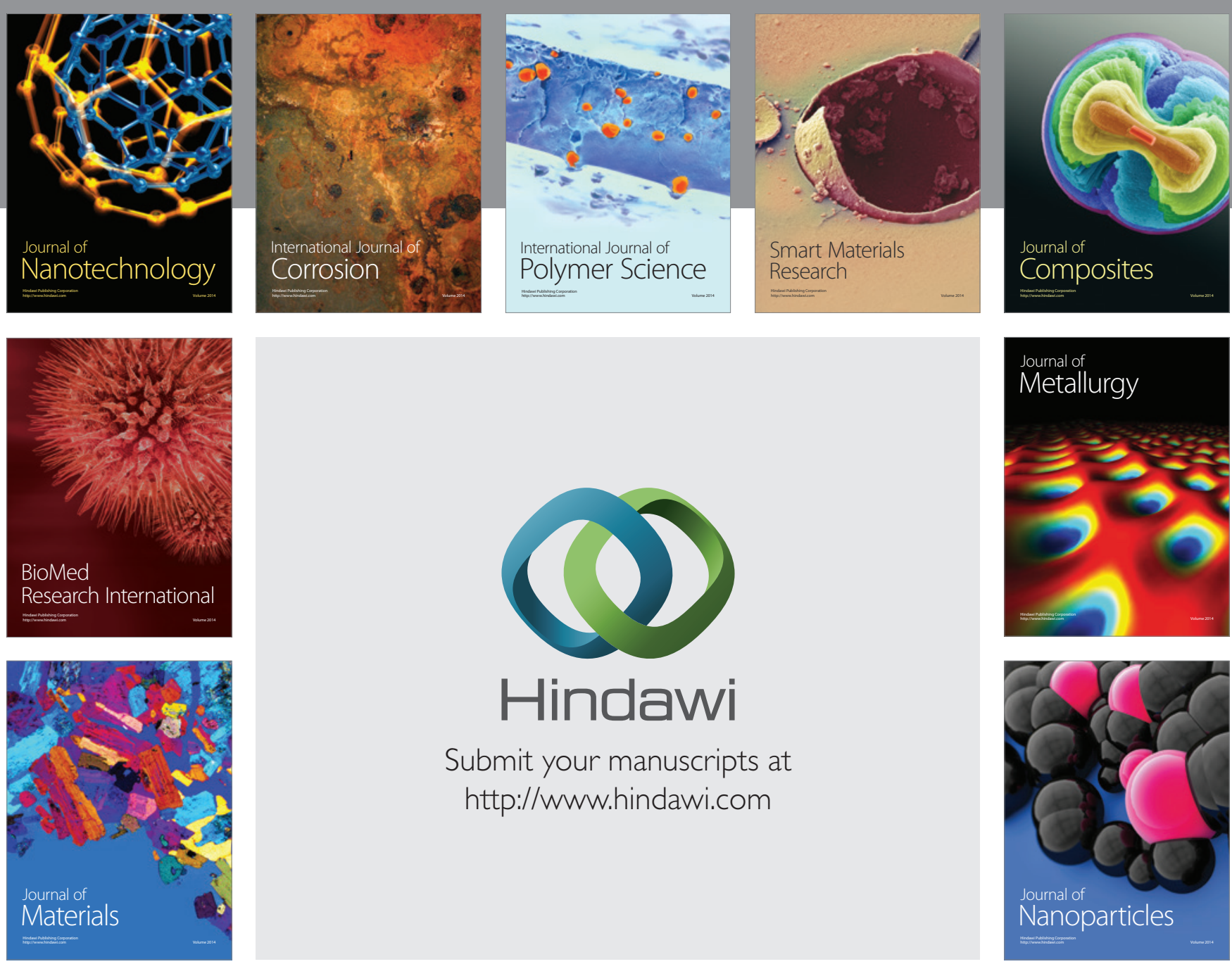

Submit your manuscripts at http://www.hindawi.com
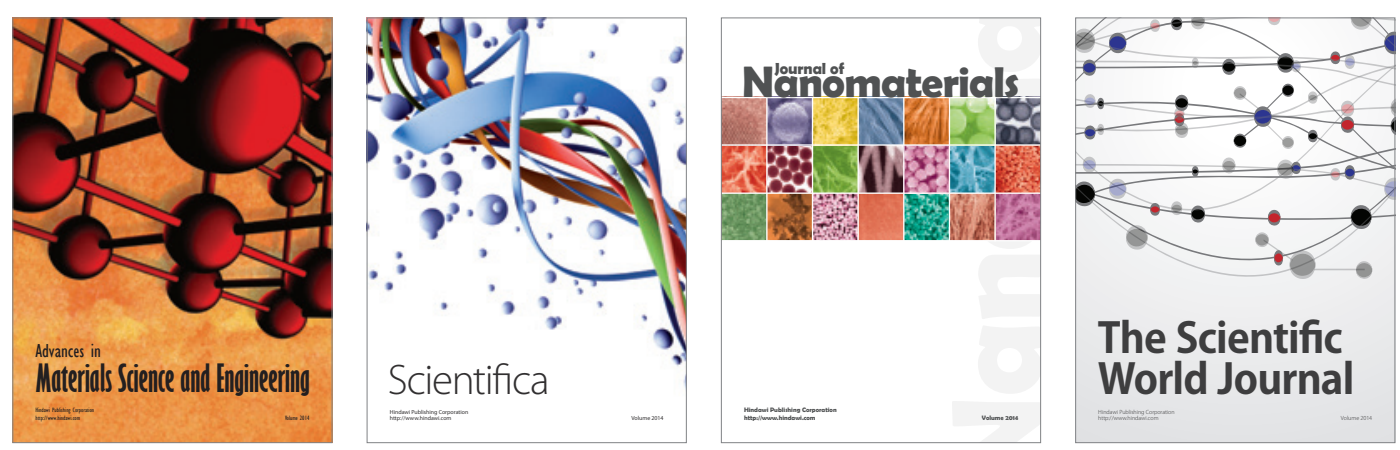

\section{The Scientific World Journal}
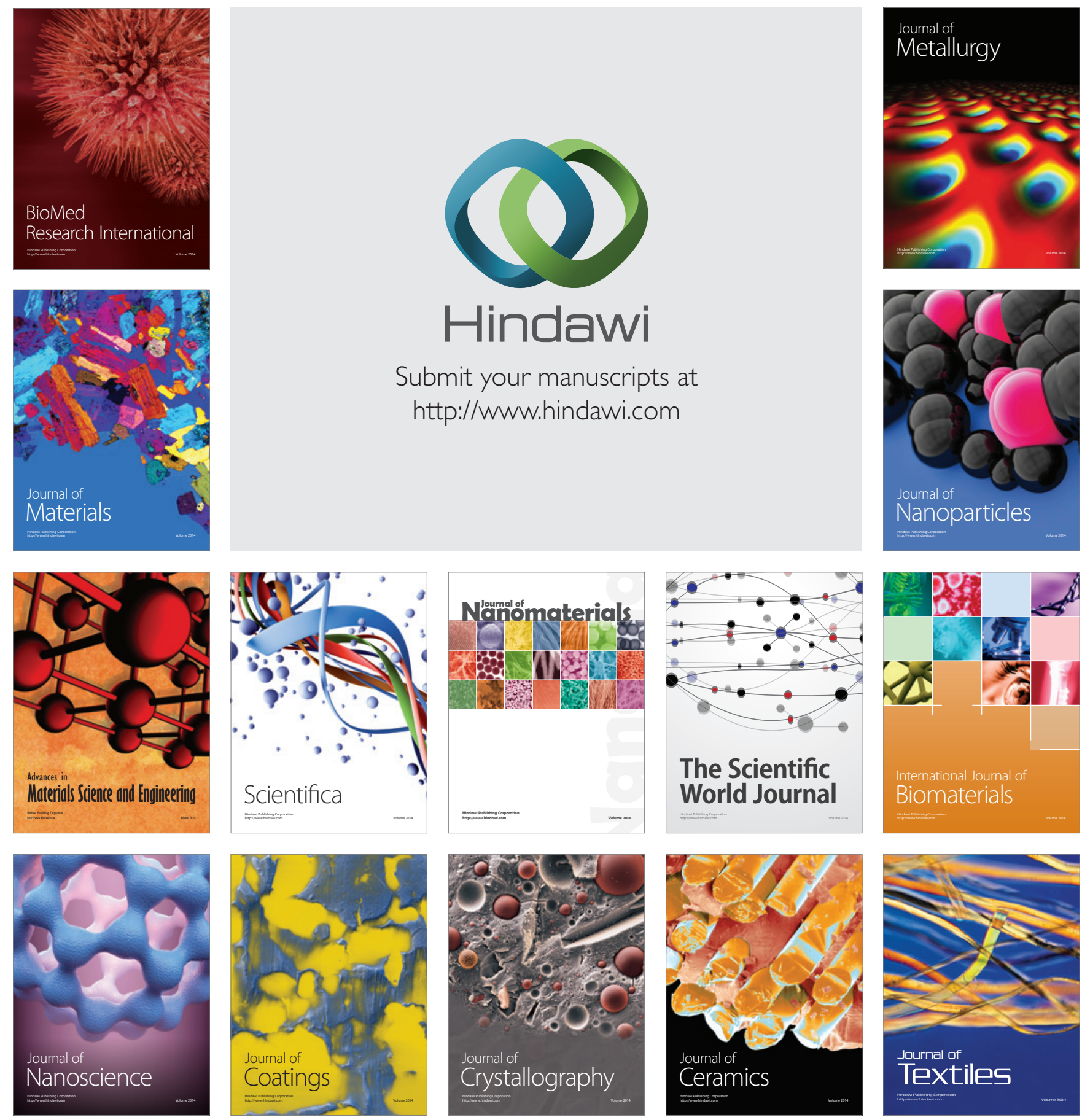